\title{
Effects of a single dose of preoperative pregabalin and gabapentin for acute postoperative pain: a network meta-analysis of randomized controlled trials
}

This article was published in the following Dove Press journal:

Journal of Pain Research

\author{
Jiaqi $\mathrm{Hu}^{1,2}$ \\ Dongdong Huang ${ }^{3}$ \\ Minpu $\mathrm{Li}^{1,2}$ \\ Chao Wu ${ }^{1,2}$ \\ Juan Zhang ${ }^{2}$
}

'Department of Anesthesiology, Zhejiang Chinese Medical University,

Hangzhou, China; ${ }^{2}$ Department of Anesthesiology, First Affiliated Hospital, Zhejiang Chinese Medical University, Hangzhou, China;

${ }^{3}$ Department of Pathology, Key Laboratory of Disease Proteomics of Zhejiang Province, School of Medicine, Zhejiang University, Hangzhou, China
Correspondence: Juan Zhang Department of Anesthesiology, First Affiliated Hospital, Zhejiang Chinese Medical University, 54 Youdian Road, Hangzhou 310006, Zhejiang, China

Tel +86 I3958I5 0569

Email zhangjuanyisheng@163.com
Background: Pregabalin (PGB) and gabapentin (GBP) are current and emerging drugs in the field of pre-emptive preoperative analgesia. However, the role of PGB or GBP in acute postoperative pain management still remains elusive.

Materials and methods: We conducted a comprehensive literature search of articles published by December 3, 2017. A total of 79 randomized controlled trials with 6,201 patients receiving single-dose premedication were included. Through a network meta-analysis (NMA), we validated the analgesic effect and incidence of adverse events by using various doses of PGB or GBP administration.

Results: NMA results suggested that the analgesic effect may be dose related. For 24-hour opioid consumption, a consistent decrease was found with the increase in the dose of PGB or GBP. For 24-hour pain score at rest, a high dose ( $\geq 150 \mathrm{mg}$ ) of PGB was more effective in decreasing pain score than a dose of $75 \mathrm{mg}$, and a high dose ( $\geq 900 \mathrm{mg}$ ) of GBP reduced pain intensity than doses of 300 or $600 \mathrm{mg}$. Moreover, the incidence of adverse reactions varied with varying doses of PGB or GBP.

Conclusion: A dose-response relationship was detected in opioid consumption and postoperative pain for a single-dose preoperative administration of PGB and GBP. Making reasonable choice of drugs and dosage may prevent the occurrence of adverse reactions.

Keywords: PGB, GBP, single dose, acute postoperative pain, network meta-analysis

\section{Introduction}

Acute postoperative pain associated with surgical wounds is commonly encountered in most patients after a surgical procedure. ${ }^{1}$ Additionally, improper postoperative pain management is significantly related to higher risk of occurrence of severe complications to patients, such as delayed trauma recovery, pulmonary embolism, as well as myocardial ischemia. ${ }^{2-4}$

Since pre-emptive preoperative analgesia was first proposed by Wall in 1988, over the years it has been gradually regarded as an intervention given before incision, facilitating advance mobilization and functional rehabilitation after surgery. ${ }^{5-7}$ Preemptive analgesia focuses on reducing postoperative opioid consumption and pain levels, decreasing the incidence of adverse events and improving patient satisfaction. Several pre-emptive analgesic regimens have been tried in the perioperative period, including opioids, nonsteroidal anti-inflammatory drugs, and so on. ${ }^{8,9}$ Pregabalin 
(PGB) or gabapentin (GBP) is a current and emerging drug in this field. Although its use for the management of postoperative pain is off-label, its perioperative oral use has become widespread. So far, many meta-analyses have investigated the efficacy of perioperative PGB or GBP administration for preventing acute postoperative pain. However, the role of PGB or GBP in acute postoperative pain management still remains elusive. For instance, the study conducted by Jiang et $\mathrm{al}^{10}$ showed that PGB appeared to be efficacious in providing relief from postoperative pain, reducing analgesic consumption, and lowering the risk of nausea following spine surgery. Nevertheless, Eipe et $\mathrm{al}^{11}$ demonstrated that the analgesic effectiveness of PGB was significantly limited to surgery associated with pronociceptive mechanisms. Additionally, previous studies were largely restricted to specific doses or methods of perioperative PGB or GBP administration. ${ }^{10,11}$ Consequently, in the present study, we aim to compare the analgesic effect and incidence of adverse events by administering different doses of PGB or GBP before surgery, and we expect to provide more insights into the optimal dose and drug selection of preemptive analgesics.

\section{Materials and methods Strategy and criteria of search}

The following databases were searched: PubMed, Embase, and the Cochrane Library with the last update by December 3, 2017. The corresponding search term combinations were ("pregabalin" or "gabapentin") AND ("pain" or "analgesia") AND ("random*"). After excluding duplicate studies, we screened eligible studies manually by reviewing the titles, abstracts, and full papers.

Inclusion criteria: randomized clinical trials were included if they satisfied the following selection criteria: 1) premedication with single dose of PGB or GBP; 2) acute postoperative pain; and 3) operation under intravertebral anesthesia or general anesthesia.

Exclusion criteria: 1) multiple-dose oral administration of PGB and GBP (long-term preoperative administration or postoperative administration); 2) chronic postoperative pain; 3) operation under local anesthesia; 4) unable to extract any data; and 5) not published in English or Chinese.

\section{Outcomes}

Eight groups were set up by the dose treatments of PGB and GBP: placebo (PBO), PGB 75 mg, PGB 150 mg, PGB 300 mg, GBP 300 mg, GBP 600 mg, GBP $900 \mathrm{mg}$, and GBP $1,200 \mathrm{mg}$.

Primary outcomes (analgesic effect): 1) opioid consumption, 2) pain score at rest (visual analog scale or numeric rating scale score), and 3 ) pain score at movement. (All data were recorded within 24 hours after surgery.)

Secondary outcomes (adverse events): 1) PONV (postoperative nausea and vomiting within 24 hours after surgery); 2) nausea; 3) vomiting; and 4) dizziness.

\section{Data extraction}

The corresponding data were independently extracted from the selected studies by two independent investigators, and any controversies were resolved through consultation with the third reviewer. The following data were acquired from qualified studies and performed in Supplemental Digital Content: first author, published year, sample size, sex, type of surgery and anesthesia, PGB or GBP administration time, and clinical outcomes. The Cochrane Collaboration's Risk of Bias Tool was used for randomized controlled trials to estimate the quality assessment of the included study. ${ }^{12}$

\section{Statistical analysis}

A network meta-analysis (NMA) was conducted by integrating both direct and indirect evidence by using STATA software (version 14.0). We used PBO as a reference treatment in all analyses. Additionally, standardized mean difference (SMD) was used to estimate the outcomes (pain score at rest, pain score at movement, and opioid consumption) of the different doses of PGB and GBP. Moreover, OR was used to describe the outcomes of PONV, nausea, vomiting, and dizziness. Surface under the cumulative ranking curve (SUCRA) was conducted to represent the corresponding ranking of each outcome, and the higher the SUCRA values, the more preferable the intervention. After that, the assessment of the degree of inconsistency between direct and indirect evidence in each loop was conducted by using the node-splitting method. Also, risk of publication bias was indicated by funnel plots. Through sensitivity analyses, we considered opioid consumption as the most objective outcome, which was the most reported and had the largest heterogeneity variance. Our sensitivity analyses consisted of excluding studies that reported median instead of mean. The mean estimate was equal to the median, while SD approximates the quartile range, divided by 1.35 or the range divided by 4 . 


\section{Results}

\section{Description of included studies}

As Figure 1 illustrates, 4,785 records were retrieved from the PubMed, Embase, and Cochrane Library in the initial

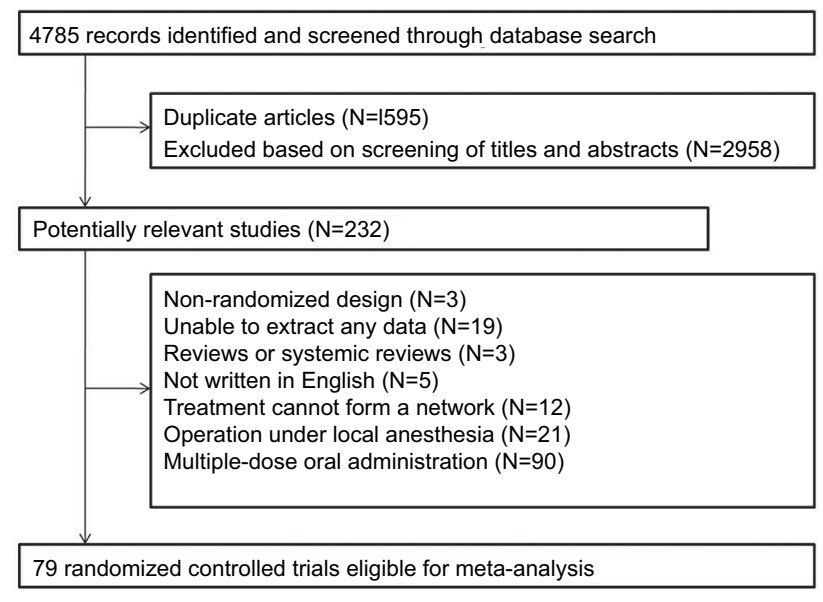

Figure I Flow chart of literature search and study selection, inclusion and exclusion. literature search. After exclusion of duplicate articles and screening of titles and abstracts, 232 citations remained for further analysis. Finally, 79 randomized controlled trials with 6,201 patients were subject to full-text review. ${ }^{13-91}$ These studies were performed from 2002 to 2017 in 23 countries. Patients included in the studies underwent various types of surgeries: obstetrics and gynecology surgery (22.8\%), spinal surgery (10.1\%), orthopedic joint surgery (17.7\%), urology surgery (7.6\%), visceral surgery (16.4\%), cardiac surgery (3.8\%), and others (20.3\%). Additionally, 62 studies (78.5\%) used general anesthesia and the others (21.5\%) used spinal anesthesia. The administration time varied between these studies: $(29.1 \%) \leq 1$ hour before surgery, $(41.8 \%)>1$ hour before surgery, $(17.7 \%) \leq 1$ hour before anesthesia, and $(10.1 \%)>1$ hour before anesthesia. One study did not provide details of the administration time (Table S1). The network of eligible comparisons is presented in Figure 2. In addition, 62 studies were two-arm trials (two of them were based on comparison between PGB and GBP), 13 were three-arm trials (three test samples were

A

B

C

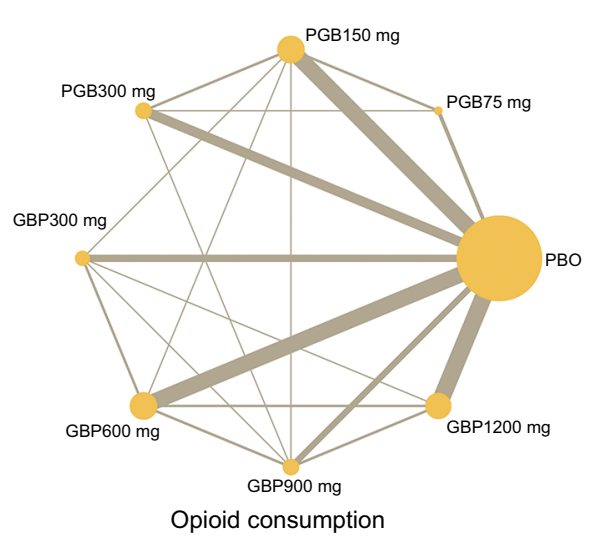

Opioid consumption

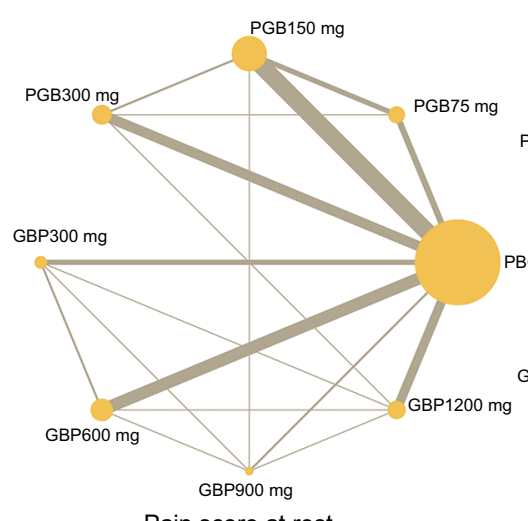

Pain score at rest

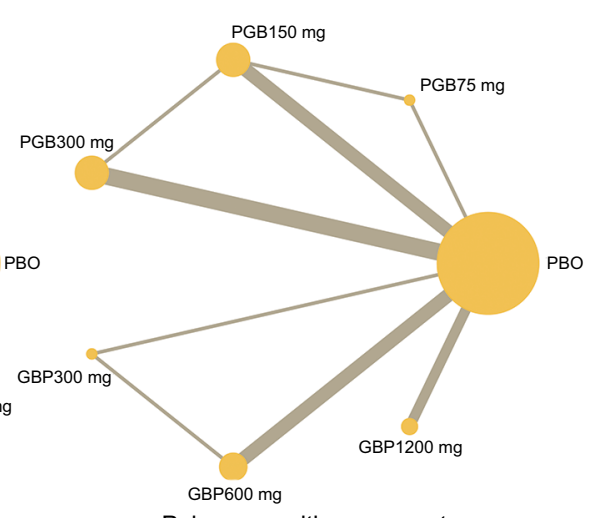

Pain score with movement

$$
\text { D }
$$

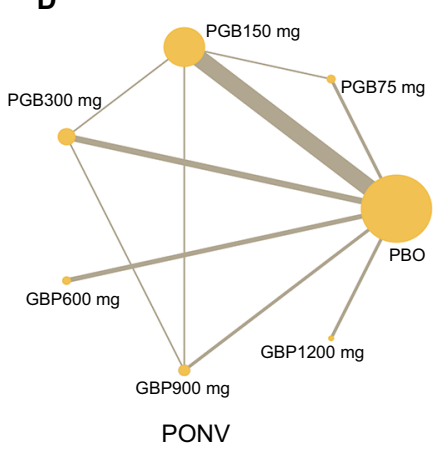

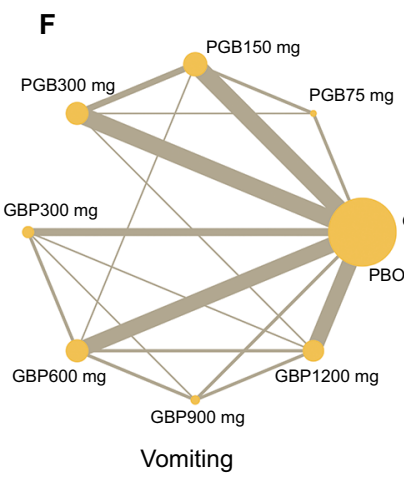

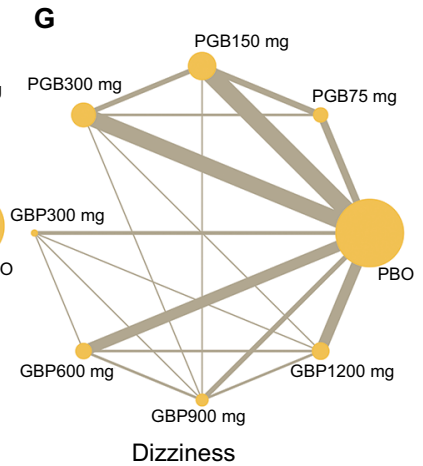

Figure 2 Network plots of eligible comparisons of all interventions including PBO, PGB 75 mg, PGB 150 mg, PGB 300 mg, GBP 300 mg, GBP 600 mg, GBP 900 mg, and GBP I, $200 \mathrm{mg}$.

Notes: (a) Network plots of opioid consumption. (b) Network plots of pain score at rest. (c) Network plots of pain score with movement. (d) Network plots of PONV. (e) Network plots of nausea. (f) Network plots of vomiting. (g) Network plots of dizziness. The size of each node is proportional to the number of sample size.

Abbreviations: GBP, gabapentin; PBO, placebo; PGB, pregabalin; PONV, postoperative nausea and vomiting within 24 hours after surgery. 
involved: PGB, GBP, and PBO), two were four-arm trials, and one was five-arm trial.

\section{Primary outcomes (analgesic effect)}

Fifty-two studies, including a total of 3,827 patients, reported data for postoperative opioid consumption. All interventions consumed less opioids than PBO, and administration of increasing dose of PGB or GBP significantly decreased the consumption of opioids (Figure 3). The following results were obtained: PGB $150 \mathrm{mg}$ vs PBO: SMD -1.66, 95\% CI -2.28 to -1.03 ; PGB $300 \mathrm{mg}$ vs PBO: SMD $-1.86,95 \% \mathrm{CI}$ -2.68 to -1.03 ; GBP $300 \mathrm{mg}$ vs PBO: SMD $-0.98,95 \% \mathrm{CI}$ -1.86 to -0.10$)$; GBP $600 \mathrm{mg}$ vs PBO: SMD $-1.14,95 \% \mathrm{CI}$ -1.77 to -0.50 ; GBP $900 \mathrm{mg}$ vs PBO: SMD $-1.64,95 \% \mathrm{CI}$ -2.60 to -0.67 ; GBP 1,200 mg vs PBO: SMD $-1.86,95 \%$ $\mathrm{CI}-2.51$ to -1.21 . No significant differences were found between the PGB $75 \mathrm{mg}$ and control groups (PGB $75 \mathrm{mg}$ vs PBO: SMD $-0.18,95 \%$ CI -1.46 to 1.09 ). SUCRA curve graph is shown in Figure 4. The four largest SUCRA values for postoperative opioid consumption were as follows: GBP 1,200 mg (81.1), PGB 300 mg (80.1), PGB 150 mg (70.9), and GBP $900 \mathrm{mg}$ (69.4).

Forty-eight studies, including a total of 3,664 patients, reported data for pain score at rest. Patients with PGB $(150 / 300 \mathrm{mg})$ and GBP (900/1,200 mg) exhibited significantly less pain compared with those with PBO (Figure 3). The results were as follows: PGB $150 \mathrm{mg}$ vs PBO: SMD $-0.96,95 \% \mathrm{CI}-1.32$ to -0.60 ; PGB $300 \mathrm{mg}$ vs PBO: SMD $-0.50,95 \% \mathrm{CI}-0.93$ to -0.07 ; GBP $900 \mathrm{mg}$ vs PBO: SMD $-1.11,95 \% \mathrm{CI}-1.98$ to -0.24 ; GBP $1,200 \mathrm{mg}$ vs PBO: SMD $-0.89,95 \% \mathrm{CI}-1.36$ to -0.43 , and no significant differences were found between patients taking others doses and PBO. The three largest SUCRA values for pain score at rest were as follows: GBP $900 \mathrm{mg}$ (86.1), PGB $150 \mathrm{mg}$ (83.6), and GBP 1,200 mg (77.6) (Figure 4).

Fifteen studies, including a total of 1,215 patients, reported data for pain score at movement. No significant differences were found between any of the interventions and control

A

Opioid consumption

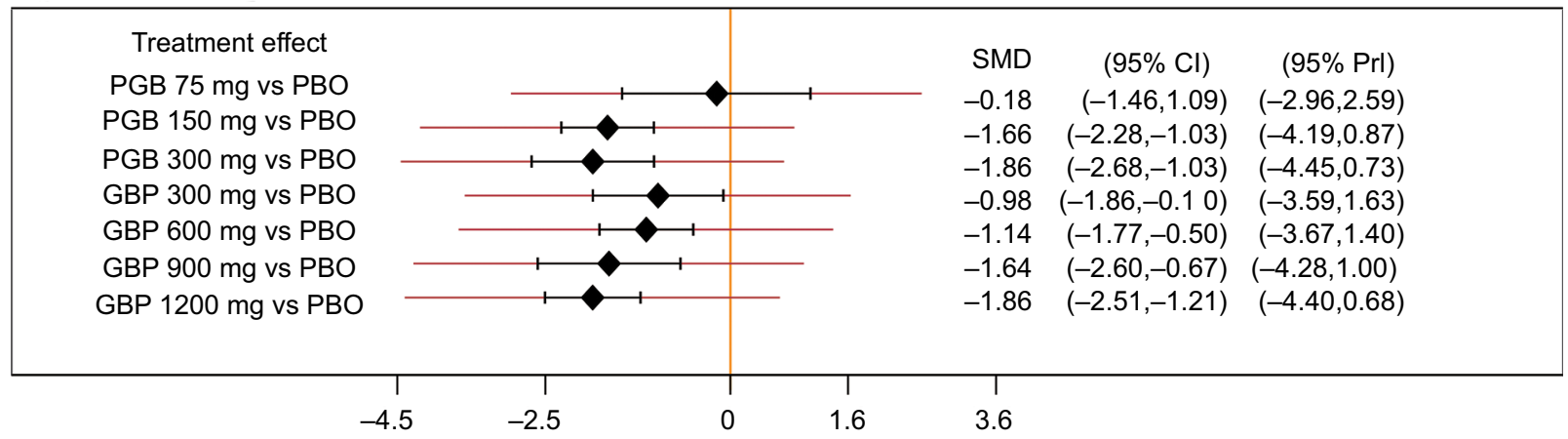

Heterogeneity variance $=1.49$

B Pain score at rest

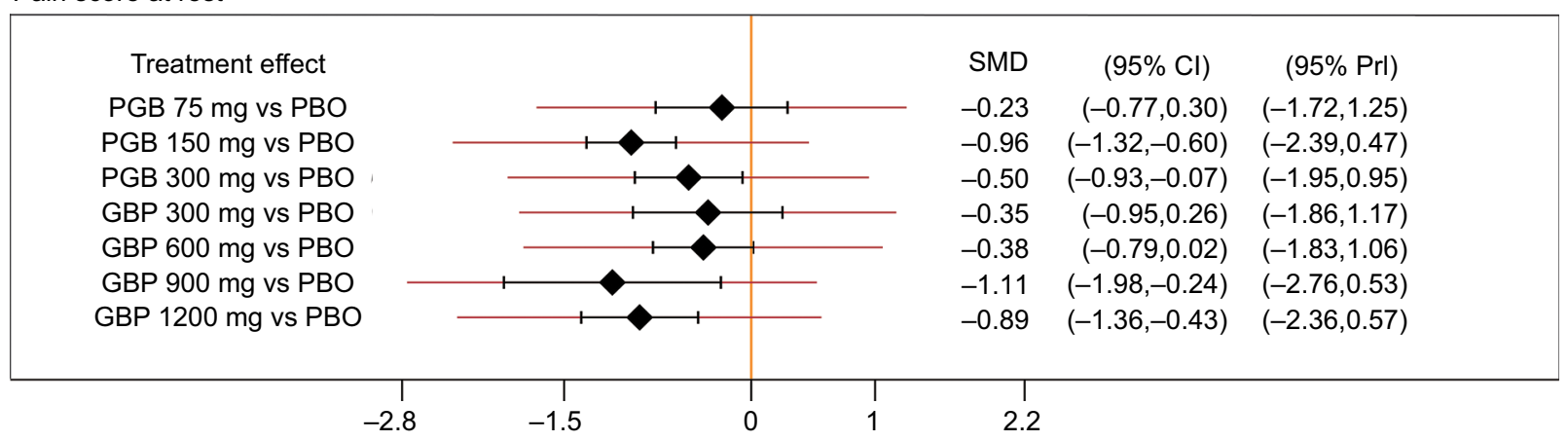

Heterogeneity variance $=0.47$

Figure 3 Forest plots of all interventions.

Notes: (a) Forest plots of the association between all interventions and opioid consumption. (b) Forest plots of the association between all interventions and pain score at rest. Patients with PGB (I50/300 mg) and GBP (900/I,200 mg) exhibited significantly less pain compared with those with PBO.

Abbreviations: GBP, gabapentin; PBO, placebo; PGB, pregabalin; SMD, standardized mean difference. 
A

$\underline{\text { Opioid consumption }}$
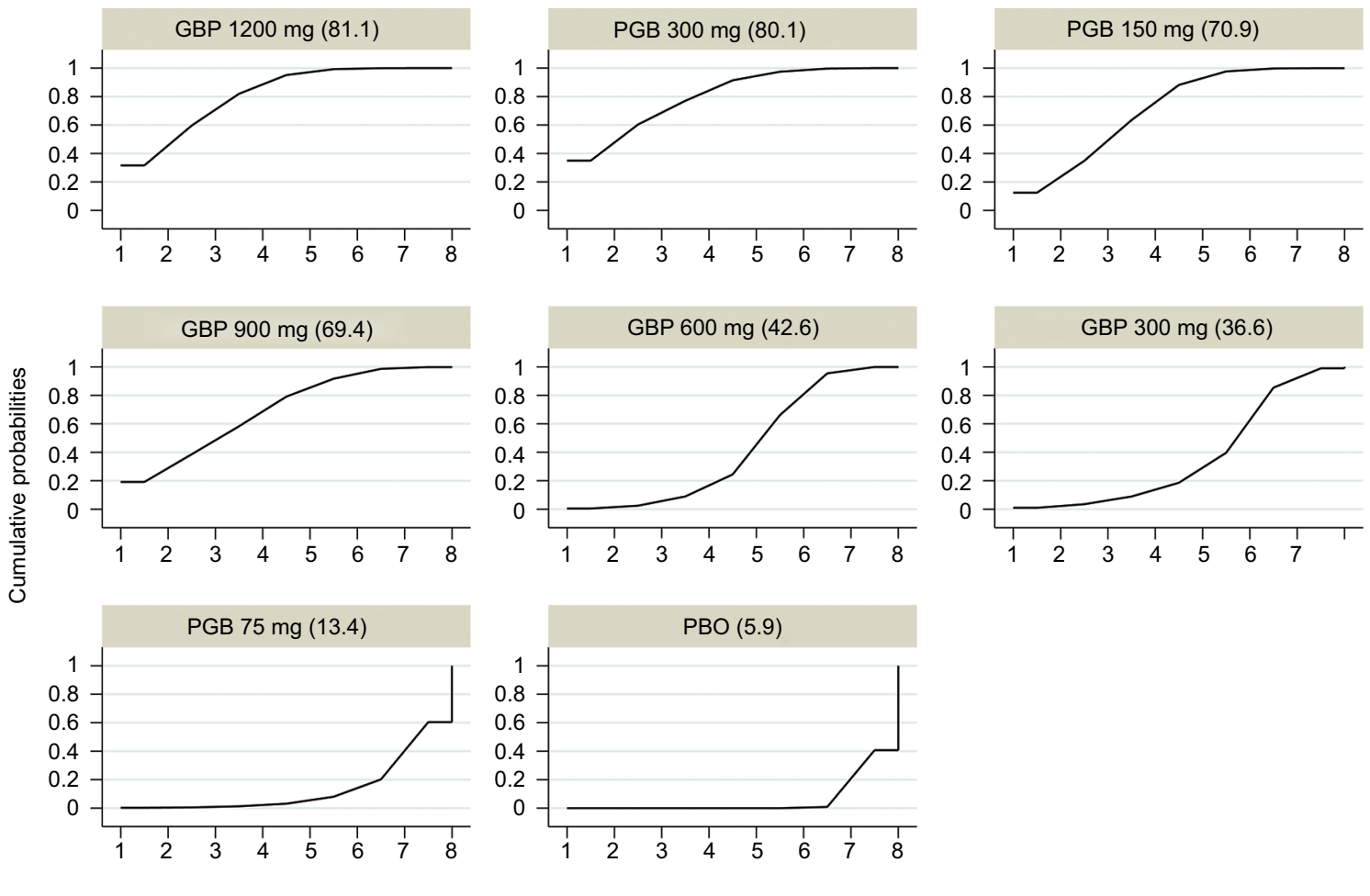

B

Pain score at rest
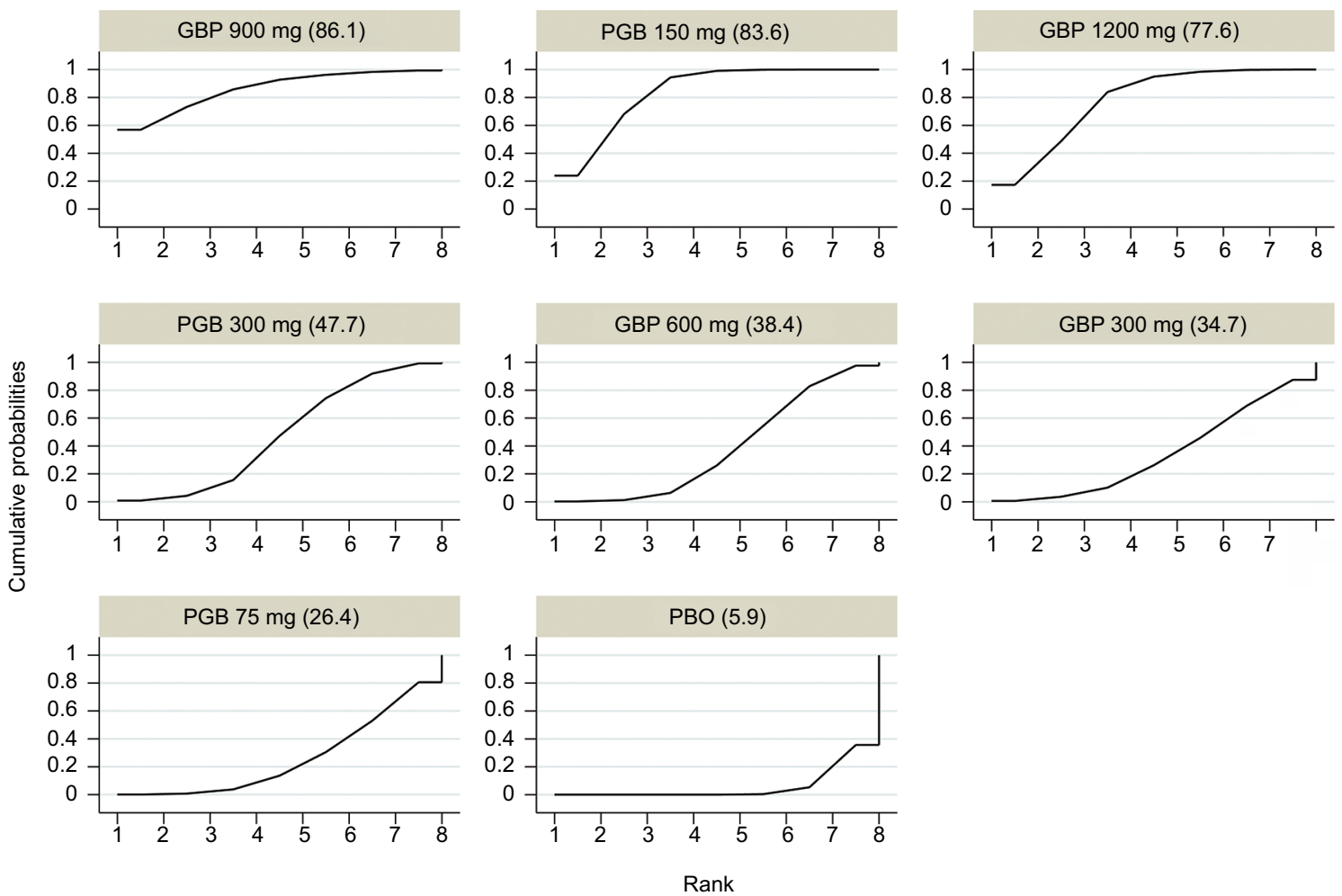

Figure 4 Ranking of SUCRA values.

Notes: (a) Ranking of SUCRA values of opioid consumption. (b) Ranking of SUCRA values of pain score at rest.

Abbreviations: GBP, gabapentin; PBO, placebo; PGB, pregabalin; SUCRA, surface under the cumulative ranking curve. 
groups. Only the SUCRA values of GBP 1,200 mg (78.3) and PGB $150 \mathrm{mg}$ (68.0) were larger than PBO (50.9) (Table 1).

\section{Secondary outcomes (adverse events)}

Overall, PGB $300 \mathrm{mg}$ reduced the incidence of PONV (PGB 300 mg vs PBO: OR 0.18, 95\% CI 0.09, 0.37) and nausea
(PGB 300 mg vs PBO: OR 0.50, 95\% CI 0.35, 0.72) compared with the control groups. In addition, patients with GBP 1,200 mg showed higher incidence of PONV (GBP 1,200 mg vs PBO: OR 5.21, 95\% CI 1.48, 18.34). However, incidence of dizziness increased when PGB $150 \mathrm{mg}$ or PGB $300 \mathrm{mg}$ was used (PGB 150 mg vs PBO: OR 1.94, 95\% CI 1.10, 3.42;

Table I SUCRA value and effect size in comparison to PBO

\begin{tabular}{|c|c|c|c|c|c|}
\hline Pain score with movement & Study & Patient & SUCRA & SMD & $95 \% \mathrm{Cl}$ \\
\hline GBP I,200 mg & 3 & 85 & 78.3 & -0.4 & $(-1.25,0.46)$ \\
\hline PGB I50 mg & 4 & 186 & 68.0 & -0.22 & $(-0.91,0.48)$ \\
\hline PBO & 15 & 542 & 50.9 & & \\
\hline PGB 75 mg & 1 & 45 & 47.8 & 0.03 & $(-1.26,1.32)$ \\
\hline GBP $300 \mathrm{mg}$ & I & 44 & 45.3 & 0.11 & $(-1.19,1.40)$ \\
\hline PGB 300 mg & 5 & 183 & 44.2 & 0.07 & $(-0.56,0.7 I)$ \\
\hline GBP $600 \mathrm{mg}$ & 4 & 130 & 15.6 & 0.52 & $(-0.22,1.26)$ \\
\hline Total number of patients & 1,215 & & & & \\
\hline Incidence of PONV & Study & Patient & SUCRA & OR & $95 \% \mathrm{Cl}$ \\
\hline PGB $300 \mathrm{mg}$ & 4 & 119 & 97.1 & 0.18 & $(0.09,0.37)$ \\
\hline GBP $600 \mathrm{mg}$ & 3 & 141 & 80.4 & 0.32 & $(0.16,0.65)$ \\
\hline GBP $900 \mathrm{mg}$ & 2 & 60 & 53.1 & 0.59 & $(0.23,1.53)$ \\
\hline PGB 75 mg & 2 & 80 & 52.5 & 0.6 & $(0.24,1.50)$ \\
\hline PGB I50 mg & 11 & 384 & 44.1 & 0.74 & $(0.50,1.09)$ \\
\hline PBO & 20 & 680 & 22.4 & & \\
\hline GBP I,200 mg & 2 & 52 & 0.3 & 5.21 & $(1.48,18.34)$ \\
\hline Total number of patients & 1,516 & & & & \\
\hline Incidence of nausea & Study & Patient & SUCRA & OR & $95 \% \mathrm{Cl}$ \\
\hline PGB $300 \mathrm{mg}$ & 11 & 364 & 89.0 & 0.5 & $(0.35,0.72)$ \\
\hline GBP $300 \mathrm{mg}$ & 5 & 157 & 74.4 & 0.58 & $(0.33,1.01)$ \\
\hline GBP I,200 mg & 12 & 327 & 53.8 & 0.73 & $(0.48,1.10)$ \\
\hline GBP $600 \mathrm{mg}$ & 11 & 355 & 51.0 & 0.75 & $(0.53,1.08)$ \\
\hline GBP $900 \mathrm{mg}$ & 2 & 45 & 44.3 & 0.82 & $(0.31,2.13)$ \\
\hline PGB 75 mg & 2 & 73 & 37.1 & 0.87 & $(0.4 I, 1.85)$ \\
\hline PGB I50 mg & 11 & 391 & 34.9 & 0.86 & $(0.59,1.25)$ \\
\hline PBO & 41 & 1,323 & 15.4 & & \\
\hline Total number of patients & 3,035 & & & & \\
\hline Incidence of vomiting & Study & Patient & SUCRA & OR & $95 \% \mathrm{Cl}$ \\
\hline GBP $900 \mathrm{mg}$ & 2 & 45 & 73.6 & 0.42 & $(0.08,2.16)$ \\
\hline GBP I,200 mg & 9 & 246 & 67.6 & 0.58 & $(0.34,1.00)$ \\
\hline PGB 75 mg & 2 & 73 & 56.2 & 0.65 & $(0.27,1.57)$ \\
\hline PGB $300 \mathrm{mg}$ & 11 & 375 & 53.6 & 0.69 & $(0.44,1.09)$ \\
\hline GBP $600 \mathrm{mg}$ & 9 & 300 & 53.4 & 0.7 & $(0.41,1.18)$ \\
\hline GBP $300 \mathrm{mg}$ & 5 & 157 & 44.6 & 0.74 & $(0.34,1.61)$ \\
\hline PGB I50 mg & II & 386 & 37.2 & 0.81 & $(0.5 \mathrm{I}, \mathrm{I} .3 \mathrm{I})$ \\
\hline PBO & 37 & 1,214 & 13.9 & & \\
\hline Total number of patients & 2,796 & & & & \\
\hline Incidence of dizziness & Study & Patient & SUCRA & OR & $95 \% \mathrm{Cl}$ \\
\hline GBP $600 \mathrm{mg}$ & 9 & 289 & 75.1 & 0.93 & $(0.44,1.97)$ \\
\hline PBO & 41 & $\mathrm{I}, 342$ & 72.8 & & \\
\hline PGB 75 mg & 6 & 210 & 69.8 & 1 & $(0.42,2.39)$ \\
\hline GBP 300 mg & 3 & 78 & 55.0 & 1.18 & $(0.26,5.37)$ \\
\hline GBP I,200 mg & 9 & 244 & 47.8 & 1.38 & $(0.67,2.82)$ \\
\hline GBP 900 mg & 4 & 105 & 43.4 & 1.53 & $(0.54,4.33)$ \\
\hline PGB I50 mg & 14 & 512 & 25.3 & 1.94 & $(1.10,3.42)$ \\
\hline PGB $300 \mathrm{mg}$ & 13 & 425 & 10.8 & 2.49 & $(1.46,4.23)$ \\
\hline Total number of patients & 3,205 & & & & \\
\hline
\end{tabular}

Abbreviations: GBP, gabapentin; PBO, placebo; PGB, pregabalin; SUCRA, surface under the cumulative ranking curve; SMD, standardized mean difference. 
PGB 300 mg vs PBO: OR 2.49, 95\% CI 1.46, 4.23). No significant differences were found between the interventions and control groups for incidence of vomiting (Table 1). Complete forest plots of summary effects are displayed in Figure S1.

\section{Risk of bias assessment}

The risk of bias assessment is presented in Figure 5 as well as in Table S2. The most common high risk of bias was selective reporting $(16.5 \%)$, which principally resulted from the consideration of incomplete outcome data. As illustrated in Figure S2, no risk of publication bias was found for any outcomes. A contribution plot showed the risk of bias of each direct or indirect comparison, which is shown in Figure S3.

\section{Sensitivity analyses}

We conducted sensitivity analyses for opioid consumption by excluding studies only reporting median instead of mean $(\mathrm{n}=8)$. SUCRA ranking for overall treatment was not markedly affected: PGB $300 \mathrm{mg}$ (83.6), GBP 1,200 mg (82.4), GBP $900 \mathrm{mg}$ (63.6.), PGB $150 \mathrm{mg}$ (61.2), PGB $75 \mathrm{mg}$ (42.8), GBP $600 \mathrm{mg}$ (34.8), GBP $300 \mathrm{mg}$ (29.1), and PBO (2.5). Heterogeneity variance was 1.19 (Figure S4).

\section{Inconsistency}

Node-splitting method was used to assess inconsistency in the analysis. Only a few loops had inconsistent results for each outcome (Figure S5).

\section{Discussion}

Pre-emptive analgesia given before incision focuses on managing postoperative pain including decreasing the consumption of analgesics as well as conferring neuroprotective characteristics. ${ }^{9}$ Although many meta-analyses have investigated the analgesic efficacy of perioperative PGB or GBP administration so far, the role of PGB or GBP in acute post-

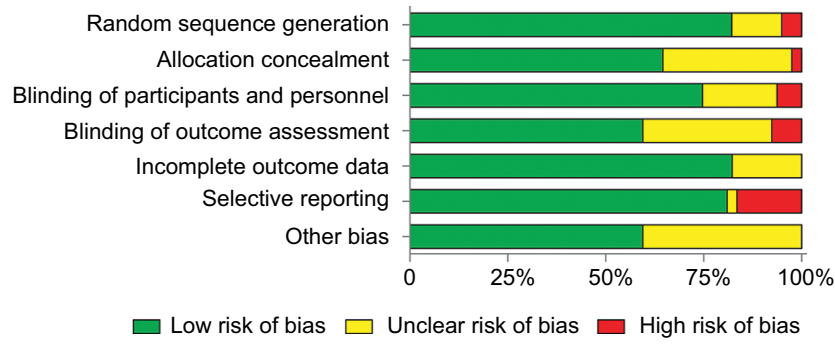

Figure 5 Risk of bias assessment.

Note: The most common high risk of bias was selective reporting (16.5\%), which principally resulted from the consideration of incomplete outcome data. operative pain management still remains elusive. Moreover, few studies compared different doses of abovementioned drugs for preventing acute postoperative pain.

Recently, the study performed by Fabritius et $\mathrm{a}^{92}$ demonstrated that they could not confirm a distinct relationship between the dose of GBP and the consumption of opioids, dividing all treatments into subgroups despite single or multiple doses, preoperative or postoperative administrations. In the present study, we presented an NMA to validate the effect of analgesic and risk of adverse events by a series of doses of PGB or GBP administration. Interestingly, our results indicated that a dose-response relationship was detected in analgesic effect of preoperative PGB or GBP treatment. For 24-hour opioid consumption, as an objective marker for measurements of pain relief in postoperative studies, a consistent decrease was found with the increase in the dose of GBP or PGB. For 24-hour pain score at rest, a high dose $(\geq 150 \mathrm{mg})$ of PGB was more effective in decreasing pain score than dose of $75 \mathrm{mg}$, and a high dose ( $\geq 900 \mathrm{mg}$ ) of GBP reduced pain intensity than doses of 300 or $600 \mathrm{mg}$.

Recent paper suggested that PGB and GBP may share a similar mechanism in the treatment and prevention of postoperative pain, affecting one type of calcium channel to decrease the release of some neurotransmitters such as noradrenaline.$^{93-95}$ Additionally, a nonlinear process of saturable absorption exists in orally administered GBP, making its plasma concentrations less predictable. In contrast, total bioavailability of PGB remains at more than $90 \%$ regardless of dose..$^{96,97} \mathrm{~A}$ trial displayed by Ifuku et al ${ }^{98}$ suggested that effectiveness of PGB on neuropathic pain was six times that of GBP.

Previous studies have disclosed that unalleviated postoperative pain was associated with various complications such as deep veins thrombosis, increased heart rate, and blood pressure. ${ }^{88,95}$ Our analysis also indicated that preoperative single-dose administration of PGB or GBP would influence the incidence of postoperative adverse reactions. Previously, Kohli et a ${ }^{88}$ reported that the reduction of postoperative blood pressure, heart rate, as well as anxiety level was significantly related to preoperative single-dose administration of PGB. In the current study, of note, using a high dose ( $\geq 300 \mathrm{mg}$ ) of PGB preoperatively is one of the approaches to prevent PONV and nausea, but not vomiting. The underlying mechanism of preventing PONV and nausea by PGB may be as follows: 1) nausea and vomiting are one of the side effects of opioids; pre-emptive analgesia using PGB may reduce preoperative and intraoperative opioid requirements, thereby resulting in decreased incidence of PONV and nausea. 2) The 
reduction in tachykinin neurotransmission, calcium influx, as well as inflammatory response at the surgical site may explain the underlying mechanisms of anti-emetic properties of PGB. ${ }^{99,100}$

A previous meta-analysis which investigated nausea and vomiting as the primary outcomes (44 studies, $n=3,489$ ) found that GBP is associated with a reduction in postoperative nausea and vomiting. ${ }^{101}$ However, there was no significant difference between control groups and GBP in our NMA. Recent findings have established that pharmacokinetic properties vary by PGB and GBP, which might be one of the reasons for the difference in our study. Orally administered GBP achieved maximum plasma concentrations within 3-4 hours, while PGB is absorbed more rapidly and attained the maximum plasma concentrations within 1 hour. ${ }^{96}$ In addition, since we did not search for adverse effects alone in the database, the results in our study may be incomplete.

\section{Highlights}

Our NMA is the first dose-related NMA of the impact of PGB and GBP on acute postoperative pain, revealing that a suitable single dose of preoperative PGB or GBP administration has a significant effect in reducing opioid consumption and postoperative pain. In addition, our study comprehensively analyzed the analgesic effect combined with incidence of adverse events. The results suggested that a high dose $(\geq 150$ $\mathrm{mg}$ ) of PGB can increase the rate of dizziness, and a high dose ( $\geq 300 \mathrm{mg}$ ) of PGB decreases the incidence of PONV and nausea, while GBP 1,200 mg increases the rate of PONV.

\section{Limitations}

First, the heterogeneity of opioid consumption could not be absolutely explained. In the current study, sensitivity analysis based on the type of data was focused on explaining it, but the analgesic effect of PGB or GBP may be confounded by patient characteristic, ethnic status, timing of administration, type of surgery, or intraoperative medication. Therefore, further data analysis is essential to avoid these interference factors. Second, we only included end points about opioid consumption and pain score with follow-up at 24 hours postoperatively. Third, the relatively small sample size of the certain included studies may have affected the accuracy of the effect size estimation.

\section{Conclusion}

The results of our current study demonstrated that a doseresponse relationship was detected in opioid consumption and postoperative pain for a single-dose preoperative administration of $\mathrm{PGB}$ and GBP. Making reasonable choice of drugs and dosage may prevent the occurrence of adverse reactions. Future clinical trials are required to determine the differences in analgesic effect between single-dose oral administration and multiple-dose oral administration. Furthermore, the optimal doses of these medications and timing of administration of pre-emptive analgesia still require further study, which may help make the standardization and rationalization of multimodal analgesia possible.

\section{Acknowledgment}

The project was supported by the Natural Science Foundation of Zhejiang Province (LY16H290003 to Juan Zhang).

\section{Disclosure}

The authors report no conflicts of interest in this work.

\section{References}

1. American Society of Anesthesiologists Task Force on Acute Pain Management. Practice guidelines for acute pain management in the perioperative setting: an updated report by the American Society of Anesthesiologists Task Force on Acute Pain Management. Anesthesiology. 2004;100(6):1573-1581.

2. Misiołek H, Cettler M, Woroń J, Wordliczek J, Dobrogowski J, Mayzner-Zawadzka E. The 2014 guidelines for post-operative pain management. Anaesthesiol Intensive Ther. 2014;46(4):221-244.

3. Kissin I. Preemptive analgesia. Anesthesiology. 2000;93(4):1138-1143.

4. Parsons B, Schaefer C, Mann R, et al. Economic and humanistic burden of post-trauma and post-surgical neuropathic pain among adults in the United States. J Pain Res. 2013;6:459-469.

5. Katz J, Mccartney CJ. Current status of preemptive analgesia. Curr Opin Anaesthesiol. 2002;15(4):435-441.

6. Vadivelu N, Mitra S, Schermer E, Kodumudi V, Kaye AD, Urman RD. Preventive analgesia for postoperative pain control: a broader concept. Local Reg Anesth. 2014;7:17-22.

7. Wall PD. The prevention of postoperative pain. Pain. 1988;33(3): 289-290.

8. Lavand'homme P, De Kock M, Waterloos H. Intraoperative Epidural Analgesia Combined with Ketamine Provides Effective Preventive Analgesia in Patients Undergoing Major Digestive Surgery. Anesthesiology. 2005;103(4):813-820.

9. Gottschalk A. Update on preemptive analgesia. Tech Reg Anesth Pain Manag. 2003;7(3):116-121.

10. Jiang HL, Huang S, Song J, Wang X, Cao ZS. Preoperative use of pregabalin for acute pain in spine surgery: A meta-analysis of randomized controlled trials. Medicine (Baltimore). 2017;96(11):e6129.

11. Eipe N, Penning J, Yazdi F, et al. Perioperative use of pregabalin for acute pain-a systematic review and meta-analysis. Pain. 2015;156(7):1284-1300

12. Higgins JPT, Green S, editors. Cochrane Handbook for Systematic Reviews of Interventions Version 5.1.0. London: The Cochrane Collaboration; 2011. Available from http://handbook.cochrane.org.

13. Pandey CK, Karna ST, Tandon M, Pandey VK, Singh A. Comparative evaluation of prophylactic use of pregabalin, gabapentin and diclofenac sodium for prevention of succinylcholine-induced myalgia: a randomized, double-blinded study. J Postgrad Med. 2014;60(1):16-20.

14. Mardani-Kivi M, Karimi Mobarakeh M, Keyhani S, Haghighi M, Hashemi-Motlagh K, Saheb-Ekhtiari K. Arthroscopic bankart surgery: Does gabapentin reduce postoperative pain and opioid consumption? A triple-blinded randomized clinical trial. Orthop Traumatol Surg Res. 2016;102(5):549-553. 
15. Dirks J, Fredensborg BB, Christensen D, Fomsgaard JS, Flyger H, Dahl JB. A Randomized Study of the Effects of Single-dose Gabapentin versus Placebo on Postoperative Pain and Morphine Consumption after Mastectomy. Anesthesiology. 2002;97(3):560-564.

16. Kochhar A, Chouhan K, Panjiar P, Vajifdar H. Gabapentinoids as a Part of Multi-modal Drug Regime for Pain Relief following Laproscopic Cholecystectomy: A Randomized Study. Anesth Essays Res. 2017;11(3):676-680.

17. Syal K, Goma M, Dogra RK, Ohri A, Gupta AK, Goel A. "Protective Premedication": A Comparative Study of Acetaminophen, Gabapentin and Combination of Acetaminophen with Gabapentin for PostOperative Analgesia. J Anaesth Clin Pharmacol. 2010;26(4):531-536.

18. Pandey CK, Priye S, Singh S, Singh U, Singh RB, Singh PK. Preemptive use of gabapentin significantly decreases postoperative pain and rescue analgesic requirements in laparoscopic cholecystectomy. Can J Anaesth. 2004;51(4):358-363.

19. Al-Mujadi H, A-Refai AR, Katzarov MG, Dehrab NA, Batra YK, Al-Qattan AR. Preemptive gabapentin reduces postoperative pain and opioid demand following thyroid surgery. Can J Anaesth. 2006;53(3):268-273.

20. Montazeri K, Kashefi P, Honarmand A. Pre-emptive gabapentin significantly reduces postoperative pain and morphine demand following lower extremity orthopaedic surgery. Singapore Med J. 2007;48(8):748-751.

21. Mardani-Kivi M, Mobarakeh MK, Keyhani S, Motlagh KH, Ekhtiari KS. Is gabapentin effective on pain management after arthroscopic anterior cruciate ligament reconstruction? A triple blinded randomized controlled trial. Arch Bone Jt Surg. 2013;1(1):18-22.

22. Pandey CK, Singhal V, Kumar M, et al. Gabapentin provides effective postoperative analgesia whether administered pre-emptively or postincision. Can J Anaesth. 2005;52(8):827-831.

23. Huot M-P, Chouinard P, Girard F, Ruel M, Lafontaine ER, Ferraro P. Gabapentin does not reduce post-thoracotomy shoulder pain: a randomized, double-blind placebo-controlled study. Can J Anesth. 2008;55(6):337-343.

24. Pandey CK, Navkar DV, Giri PJ, et al. Evaluation of the optimal preemptive dose of gabapentin for postoperative pain relief after lumbar diskectomy: a randomized, double-blind, placebo-controlled study. J Neurosurg Anesthesiol. 2005;17(2):65-68.

25. Deniz MN, Sertoz N, Erhan E, Ugur G. Effects of preoperative gabapentin on postoperative pain after radical retropubic prostatectomy. $J$ Int Med Res. 2012;40(6):2362-2369.

26. Bang SR, Yu SK, Kim TH. Can gabapentin help reduce postoperative pain in arthroscopic rotator cuff repair? A prospective, randomized, double-blind study. Arthroscopy. 2010;26(9 Suppl):S106-S111.

27. Bartholdy J, Hilsted KL, Hjortsoe NC, Engbaek J, Dahl JB. Effect of Gabapentin on morphine demand and pain after laparoscopic sterilization using Filshie clips. A double blind randomized clinical trial. $B M C$ Anesthesiol. 2006;6(11):12.

28. Brogly N, Wattier JM, Andrieu G, et al. Gabapentin attenuates late but not early postoperative pain after thyroidectomy with superficial cervical plexus block. Anesth Analg. 2008;107(5):1720-1725.

29. Durmus M, But AK, Saricicek V, Toprak HI, Ersoy MO. The postoperative analgesic effects of a combination of gabapentin and paracetamol in patients undergoing abdominal hysterectomy: a randomized clinical trial. Acta Anaesthesiol Scand. 2007;51(3):299-304.

30. Turan A, Karamanlioğlu B, Memiş D, et al. Analgesic effects of gabapentin after spinal surgery. Anesthesiology. 2004;100(4):935-938.

31. Karbić VO, Škoda M, Antončić D, et al. Gabapentin-induced changes of plasma cortisol level and immune status in hysterectomized women. Int Immunopharmacol. 2014;23(2):530-536.

32. Khademi S, Ghaffarpasand F, Heiran HR, Asefi A. Effects of preoperative gabapentin on postoperative nausea and vomiting after open cholecystectomy: a prospective randomized double-blind placebocontrolled study. Med Princ Pract. 2010;19(1):57-60.

33. Khan ZH, Rahimi M, Makarem J, Khan RH. Optimal dose of preincision/post-incision gabapentin for pain relief following lumbar laminectomy: a randomized study. Acta Anaesthesiol Scand. 2011;55(3):306-312.
34. Mayell A, Srinivasan I, Campbell F, Peliowski A. Analgesic effects of gabapentin after scoliosis surgery in children: a randomized controlled trial. Paediatr Anaesth. 2014;24(12):1239-1244.

35. Menda F, Köner O, Sayın M, Ergenoğlu M, Küçükaksu S, Aykaç B. Effects of single-dose gabapentin on postoperative pain and morphine consumption after cardiac surgery. $J$ Cardiothorac Vasc Anesth. 2010;24(5):808-813.

36. Ménigaux C, Adam F, Guignard B, Sessler DI, Chauvin M. Preoperative gabapentin decreases anxiety and improves early functional recovery from knee surgery. Anesth Analgesia. 2005;100(5):1394-1399.

37. Rimaz S, Alavi CE, Sedighinejad A, Tolouie M, Kavoosi S, Koochakinejad L. Effect of gabapentin on morphine consumption and pain after surgical debridement of burn wounds: a double-blind randomized clinical trial study. Arch Trauma Res. 2012;1(1):38-43.

38. Rorarius MG, Mennander S, Suominen P, et al. Gabapentin for the prevention of postoperative pain after vaginal hysterectomy. Pain. 2004;110(1):175-181.

39. Sanders JG, Cameron C, Dawes PJD. Gabapentin in the Management of Pain following Tonsillectomy: A Randomized Double-Blind PlaceboControlled Trial. Otolaryngol Head Neck Surg. 2017;157(5):781-790.

40. Sen H, Sizlan A, Yanarates O, et al. A comparison of gabapentin and ketamine in acute and chronic pain after hysterectomy. Anesth Analg. 2009;109(5):1645-1650.

41. Siddiqui NT, Fischer H, Guerina L, Friedman Z. Effect of a preoperative gabapentin on postoperative analgesia in patients with inflammatory bowel disease following major bowel surgery: a randomized, placebo-controlled trial. Pain Pract. 2014;14(2):132-139.

42. Turan A, Karamanlioğlu B, Memiş D, Usar P, Pamukçu Z, Türe M. The analgesic effects of gabapentin after total abdominal hysterectomy. Anesth Analg. 2004;98(5):1370-1373.

43. Ajori L, Nazari L, Mazloomfard MM, Amiri Z. Effects of gabapentin on postoperative pain, nausea and vomiting after abdominal hysterectomy: a double blind randomized clinical trial. Arch Gynecol Obstet. 2012;285(3):677-682.

44. Mohammadi SS, Seyedi M. Effects of gabapentin on early postoperative pain, nausea and vomiting in laparoscopic surgery for assisted reproductive technologies. Pak J Biol Sci. 2008;11(14):1878-1880.

45. Srivastava U, Kumar A, Saxena S, Mishra AR, Saraswat N, Mishra $\mathrm{S}$. Effect of preoperative gabapentin on postoperative pain and tramadol consumption after minilap open cholecystectomy: a randomized double-blind, placebo-controlled trial. Eur J Anaesthesiol. 2010;27(4):331-335.

46. Bharti N, Bala I, Narayan V, Singh G. Effect of gabapentin pretreatment on propofol consumption, hemodynamic variables, and postoperative pain relief in breast cancer surgery. Acta Anaesthesiol Taiwan. 2013;51(1):10-13.

47. Short J, Downey K, Bernstein P, Shah V, Carvalho JC. A single preoperative dose of gabapentin does not improve postcesarean delivery pain management: a randomized, double-blind, placebo-controlled dose-finding trial. Anesth Analg. 2012;115(6):1336-1342.

48. Tomar GS, Singh F, Cherian G. Role of Preemptive Gabapentin on Postoperative Analgesia After Infraumbilical Surgeries Under Subarachnoid Block-A Randomized, Placebo-Controlled, Double-Blind Study. Am J Ther. 2017;1:1.

49. Kinney MA, Mantilla CB, Carns PE, et al. Preoperative gabapentin for acute post-thoracotomy analgesia: a randomized, double-blinded, active placebo-controlled study. Pain Pract. 2012;12(3):175-183.

50. Hamal PK, Shrestha AB, Shrestha RR. Efficacy of Preemptive Gabapentin for Lower Extremity Orthopedic surgery under Subarachnoid Block. JNMA J Nepal Med Assoc. 2015;53(200):210-213.

51. Panah Khahi M, Yaghooti AA, Marashi SH, Nadjafi A. Effect of preemptive gabapentin on postoperative pain following lower extremity orthopaedic surgery under spinal anaesthesia. Singapore Med J. 2011;52(12):879-882.

52. Clarke H, Pereira S, Kennedy D, et al. Adding gabapentin to a multimodal regimen does not reduce acute pain, opioid consumption or chronic pain after total hip arthroplasty. Acta Anaesthesiol Scand. 2009;53(8):1073-1083. 
53. Ittichaikulthol W, Virankabutra T, Kunopart M, Khamhom W, Putarawuthichai P, Rungphet S. Effects of pregabalin on post operative morphine consumption and pain after abdominal hysterectomy with/ without salphingo-oophorectomy: a randomized, double-blind trial. $J$ Med Assoc Thai. 2009;92(10):1318-1323.

54. Hegarty DA, Shorten GD. A Randomised, Placebo-controlled Trial of the Effects of Preoperative Pregabalin on Pain Intensity and Opioid Consumption following Lumbar Discectomy. Korean J Pain. 2011;24(1):22-30.

55. Ghai A, Hooda S, Wadhera R, Gupta M, Singla D. A randomized controlled trial to compare pregabalin with gabapentin for postoperative pain in abdominal hysterectomy. Saudi J Anaesth. 2011;5(3): 252-257.

56. Fujita N, Tobe M, Tsukamoto N, Saito S, Obata H. A randomized placebo-controlled study of preoperative pregabalin for postoperative analgesia in patients with spinal surgery. J Clin Anesth. 2016;31:149-153.

57. Balaban F, Yağar S, Ö A, Koç M. Güllapoğlu H. A randomized, placebocontrolled study of pregabalin for postoperative pain intensity after laparoscopic cholecystectomy. J Clin Anesth. 2012;24(3):175-178.

58. Aydoğan H, Kucuk A, Yuce HH, et al. Adding $75 \mathrm{mg}$ pregabalin to analgesic regimen reduces pain scores and opioid consumption in adults following percutaneous nephrolithotomy. Rev Bras Anestesiol. 2014;64(5):335-342.

59. Cabrera Schulmeyer MC, de la Maza J, Ovalle C, Farias C, Vives I. Analgesic effects of a single preoperative dose of pregabalin after laparoscopic sleeve gastrectomy. Obes Surg. 2010;20(12):1678-1681.

60. Ahn S, Byun SH, Park K, Ha JL, Kwon B, Kim JC. Analgesic efficacy of preemptive pregabalin administration in arthroscopic shoulder surgery: a randomized controlled trial. Can J Anaesth. 2016;63(3):283-289.

61. Hetta DF, Mohamed MA, Mohammad MF. Analgesic efficacy of pregabalin in acute postmastectomy pain: placebo controlled dose ranging study. J Clin Anesth. 2016;34:303-309.

62. Mishra R, Tripathi M, Chandola HC. Comparative clinical study of gabapentin and pregabalin for postoperative analgesia in laparoscopic cholecystectomy. Anesth Essays Res. 2016;10(2):201-206.

63. Esmat IM, Farag HM. Comparative study between paracetamol and two different doses of pregabalin on postoperative pain in laparoscopic cholecystectomy. Saudi J Anaesth. 2015;9(4):376-380.

64. Spreng UJ, Dahl V, Raeder J. Effect of a single dose of pregabalin on post-operative pain and pre-operative anxiety in patients undergoing discectomy. Acta Anaesthesiol Scand. 2011;55(5):571-576.

65. Lee C, Lee HW, Kim JN. Effect of oral pregabalin on opioid-induced hyperalgesia in patients undergoing laparo-endoscopic single-site urologic surgery. Korean J Anesthesiol. 2013;64(1):19-24.

66. Demirhan A, Tekelioglu UY, Akkaya A, et al. Effect of pregabalin and dexamethasone addition to multimodal analgesia on postoperative analgesia following rhinoplasty surgery. Aesthetic Plast Surg. 2013;37(6):1100-1106.

67. Demirhan A, Akkaya A, Tekelioglu UY, et al. Effect of pregabalin and dexamethasone on postoperative analgesia after septoplasty. Pain Res Treat. 2014;2014(2):850794.

68. Ahiskalioglu A, Ince İ, Aksoy M, Yalcin E, Ahiskalioglu EO, Kilinc A. Effects of a Single-Dose of Pre-Emptive Pregabalin on Postoperative Pain and Opioid Consumption After Double-Jaw Surgery: A Randomized Controlled Trial. J Oral Maxillofac Surg. 2016;74(1):53.e1-7.

69. Eidy M, Fazel MR, Abdolrahimzadeh H, Moravveji AR, Kochaki E, Mohammadzadeh M. Effects of pregabalin and gabapentin on postoperative pain and opioid consumption after laparoscopic cholecystectomy. Korean J Anesthesiol. 2017;70(4):434-438.

70. Alimian M, Imani F, Hassani V, Rahimzadeh P, Sharifian M, Safari S. Effects of Single-Dose Pregabalin on Postoperative Pain in Dacryocystorhinostomy Surgery. Anesth Pain Med. 2012;2(2):72-76.

71. Sagit M, Yalcin S, Polat H, Korkmaz F, Cetinkaya S, Somdas MA. Efficacy of a single preoperative dose of pregabalin for postoperative pain after septoplasty. J Craniofac Surg. 2013;24(2):373-375.
72. Agarwal A, Gautam S, Gupta D, Agarwal S, Singh PK, Singh U. Evaluation of a single preoperative dose of pregabalin for attenuation of postoperative pain after laparoscopic cholecystectomy. Br JAnaesth. 2008;101(5):700-704.

73. Mathiesen O, Jørgensen DG, Hilsted KL, et al. Pregabalin and dexamethasone improves post-operative pain treatment after tonsillectomy. Acta Anaesthesiol Scand. 2011;55(3):297-305.

74. Mathiesen O, Rasmussen ML, Dierking G, et al. Pregabalin and dexamethasone in combination with paracetamol for postoperative pain control after abdominal hysterectomy. A randomized clinical trial. Acta Anaesthesiol Scand. 2009;53(2):227-235.

75. Bouzia A, Tassoudis V, Karanikolas M, et al. Pregabalin Effect on Acute and Chronic Pain after Cardiac Surgery. Anesthesiol Res Pract. 2017;2017(1):2753962.

76. Kumar KP, Kulkarni DK, Gurajala I, Gopinath R. Pregabalin versus tramadol for postoperative pain management in patients undergoing lumbar laminectomy: a randomized, double-blinded, placebocontrolled study. J Pain Res. 2013;6(6):471-478.

77. Ziyaeifard M, Mehrabanian MJ, Faritus SZ, et al. Premedication with oral pregabalin for the prevention of acute postsurgical pain in coronary artery bypass surgery. Anesth Pain Med. 2015;5(1):e24837.

78. Bornemann-Cimenti H, Lederer AJ, Wejbora M, et al. Preoperative pregabalin administration significantly reduces postoperative opioid consumption and mechanical hyperalgesia after transperitoneal nephrectomy. Br J Anaesth. 2012;108(5):845-849.

79. Martinez V, Cymerman A, Ben Ammar S, et al. The analgesic efficiency of combined pregabalin and ketamine for total hip arthroplasty: a randomised, double-blind, controlled study. Anaesthesia. 2014;69(1):46-52.

80. White PF, Tufanogullari B, Taylor J, Klein K. The effect of pregabalin on preoperative anxiety and sedation levels: a dose-ranging study. Anesth Analg. 2009;108(4):1140-1145.

81. Prasad A, Bhattacharyya S, Biswas A, Saha M, Mondal S, Saha D. A comparative study of pre-operative oral clonidine and pregabalin on post-operative analgesia after spinal anesthesia. Anesth Essays Res. 2014;8(1):41-47.

82. Bafna U, Rajarajeshwaran K, Khandelwal M, Verma AP. A comparison of effect of preemptive use of oral gabapentin and pregabalin for acute post-operative pain after surgery under spinal anesthesia. $J$ Anaesthesiol Clin Pharmacol. 2014;30(3):373-377.

83. Kiatchai T, Sanansilp V, Triyasunant N, Saengprateep S, Changkittirat P, Achariyapota V. Effects of pregabalin on postoperative pain after hysterectomy under spinal anesthesia with intrathecal morphine: a randomized controlled trial. J Anesth. 2017;31(6):861-868.

84. Rajappa GC, Vig S, Bevanaguddaiah Y, Anadaswamy TC. Efficacy of Pregabalin as Premedication for Post-Operative Analgesia in Vaginal Hysterectomy. Anesth Pain Med. 2016;6(3):e34591.

85. El Kenany S, El Tahan MR. Effect of preoperative pregabalin on post-caesarean delivery analgesia: a dose-response study. Int J Obstet Anesth. 2016;26:24-31.

86. Sebastian B, Talikoti AT, Nelamangala K, Krishnamurthy D. Effect of Oral Pregabalin as Preemptive Analgesic in Patients Undergoing Lower Limb Orthopedic Surgeries under Spinal Anaesthesia. J Clin Diagn Res. 2016;10(7):UC01-UC04.

87. Khetarpal R, Kataria AP, Bajaj S, Kaur H, Singh S. Gabapentin vs pregabalin as a premedication in lower limb orthopaedics surgery under combined spinal epidural technique. Anesth Essays Res. 2016;10(2):262-267.

88. Kohli M, Murali T, Gupta R, Khan P, Bogra J. Optimization of Subarachanoid Block by Oral Pregabalin for Hysterectomy. J Anaesth Clin Pharmacol. 2011;27(1):101-105.

89. Mathiesen O, Jacobsen LS, Holm HE, et al. Pregabalin and dexamethasone for postoperative pain control: a randomized controlled study in hip arthroplasty. Br J Anaesth. 2008;101(4):535-541.

90. Mihye P, Younghoon J. Preoperative pregabalin prolongs duration of spinal anesthesia and reduces early postoperative pain: A doubleblind, randomized clinical CONSORT study. Medicine (Baltimore). 2016;95(36):e4828. 
91. Akhavanakbari G, Entezariasl M, Isazadehfar K, Mirzarahimi T. The effects of oral pregabalin on post-operative pain of lower limb orthopedic surgery: A double-blind, placebo-controlled trial. Perspect Clin Res. 2013;4(3):165-168.

92. Fabritius ML, Wetterslev J, Mathiesen O, Dahl JB. Dose-related beneficial and harmful effects of gabapentin in postoperative pain management - post hoc analyses from a systematic review with metaanalyses and trial sequential analyses. J Pain Res. 2017;10:2547-2563.

93. Taylor CP. Mechanisms of analgesia by gabapentin and pregabalincalcium channel alpha2-delta [Cavalpha2-delta] ligands. Pain. 2009;142(1-2):13-16.

94. Dauri M, Faria S, Gatti A, Celidonio L, Carpenedo R, Sabato AF. Gabapentin and pregabalin for the acute post-operative pain management. A systematic-narrative review of the recent clinical evidences. Current Drug Targets. 2009;10(8):716-733.

95. Dahl JB, Mathiesen O, Møiniche S. Protective premedication': an option with gabapentin and related drugs? Acta Anaesthesiol Scand. 2010;48(9):1130-1136
96. Bockbrader HN, Wesche D, Miller R, Chapel S, Janiczek N, Burger P. A comparison of the pharmacokinetics and pharmacodynamics of pregabalin and gabapentin. Clin Pharmacokinet. 2010;49(10):661-669.

97. Gajraj NM. Pregabalin: its pharmacology and use in pain management Anesth Analg. 2007;105(6):1805-1815.

98. Ifuku M, Iseki M, Hidaka I, Morita Y, Komatus S, Inada E. Replacement of Gabapentin with Pregabalin in Postherpetic Neuralgia Therapy. Pain Med. 2011;12(7):1112-1116.

99. Fink K, Dooley DJ, Meder WP, et al. Inhibition of neuronal $\mathrm{Ca}(2+)$ influx by gabapentin and pregabalin in the human neocortex. Neuropharmacology. 2002;42(2):229-236.

100. Fehrenbacher JC, Taylor CP, Vasko MR. Pregabalin and gabapentin reduce release of substance $P$ and CGRP from rat spinal tissues only after inflammation or activation of protein kinase C. Pain 2003;105(1-2):133-141.

101. Grant MC, Betz M, Hulse M, et al. The Effect of Preoperative Pregabalin on Postoperative Nausea and Vomiting: A Meta-analysis. Anesth Analg. 2016;123(5):1100-1107.

\section{Journal of Pain Research}

\section{Publish your work in this journal}

The Journal of Pain Research is an international, peer reviewed, open access, online journal that welcomes laboratory and clinical findings in the fields of pain research and the prevention and management of pain. Original research, reviews, symposium reports, hypothesis formation and commentaries are all considered for publication

\section{Dovepress}

The manuscript management system is completely online and includes a very quick and fair peer-review system, which is all easy to use. Visit http://www.dovepress.com/testimonials.php to read real quotes from published authors. 